\title{
Comparison of Two Analytical Methods for Detecting (1-3)-ק-D-Glucan in Pure Fungal Cultures and in Home Dust Samples
}

\author{
Y. Iossifova ${ }^{1}$, T. Reponen ${ }^{*}, 1$, M. Daines ${ }^{2}$, Linda Levin ${ }^{1}$ and G.K. Khurana Hershey ${ }^{2}$ \\ ${ }^{I}$ Department of Environmental Health, University of Cincinnati, Ohio, USA \\ ${ }^{2}$ Division of Allergy and Immunology, Cincinnati Children's Hospital Medical Center, Ohio, USA
}

\begin{abstract}
There are two methods available for the analysis of (1-3)- $\beta$-D-glucan: the Limulus Amebocyte Lysate assay (LAL) and the inhibition Enzyme Immunoassay (EIA). The aim of this study was to compare the accuracy and specificity of these two methods in detecting eight alpha and beta-glucan standards, and their sensitivity for the analysis of (1-3)- $\beta$ D-glucan content of common indoor fungal species and indoor dust samples. The results show that the LAL assay is more accurate, specific, and sensitive in measuring linear and branched $\beta$-D-glucans than the EIA. The greatest LAL-analyzed (1-3)- $\beta$-D-glucan content per spore ( $241 \mathrm{pg} /$ spore) was found with E. nigrum, which also had the largest spore size (28 $\mu \mathrm{m})$. The biomass-normalized (1-3)- $\beta$-D-glucan content of fungal spores from pure cultures was within similar range with the two assays but no correlation was found between the results from the two assays. In contrast, there was a significant correlation between the EIA and LAL-measured (1-3)- $\beta$-D-glucan concentrations $\left(\mu \mathrm{g} / \mathrm{m}^{2}\right.$ of floor area) in field dust samples.
\end{abstract}

Keywords: (1-3)- $\beta$-D-glucan, fungi, indoor, LAL, EIA.

\section{INTRODUCTION}

Exposure to fungi in occupational and indoor environments is associated with respiratory (nose and throat irritation, cough) and general symptoms (tiredness and headache), allergic reactions and organic dust toxic syndrome [1-3]. In adults, similar general and respiratory symptoms and airways inflammation have been associated with occupational and indoor exposures to (1-3)- $\beta$-D-glucan, polyglucose component of the cell wall of fungi, pollen, and some bacteria $[4,5]$. In young children, however, increased dustborne (1-3)- $\beta$-Dglucan concentrations have been associated with a decreased risk for several respiratory health outcomes (asthma, persistent wheeze at age 1-4 [6], recurrent wheezing combined with allergen sensitization in infants [7]), and with a decreased risk of sensitization to inhalant allergens [8]. This may be explained with the Hygiene hypothesis, which postulates that microbial stimulation (such as endotoxin) in early childhood induces Th1 response, which counterbalances the allergen-induced Th2 responses [7,9,10].

The biological properties of (1-3)- $\beta$-D-glucan are not dependent on cellular viability and (1-3)- $\beta$-D-glucan from dead organisms may thus be equally relevant in causing potential health effects. Therefore, exposure assessment of (13 - $\beta$-D-glucan may be a better predictor for health risk than the commonly used determination of viable fungal spores. In addition, performing (1-3)- $\beta$-D-glucan analysis is less time consuming and labor intensive than cultivation or microscopic counting of fungal spores $[5,11,12]$.

Currently there are two methods available for the analysis of (1-3)- $\beta$-D-glucan in environmental and occupational samples. One method is based upon the bioactivity of this

*Address correspondence to this author at the Department of Environmental Health, University of Cincinnati, Ohio, USA;

E-mail: REPONETA@ucmail.uc.edu molecule in the factor-G-mediated Limulus coagulation pathway - the Limulus Amebocyte Lysate assay (LAL) [13]. The other method is an Enzyme-Linked ImmunoSorbent Assay (ELISA) based on (1-3)- $\beta$-D-glucan antigen-antibody reaction; the traditional form of this assay is the inhibition Enzyme Immunoassay (EIA) [11], but also other ELISA modifications have been developed [14,15]. The EIA assay has been used mostly by European research groups $[11,16,17]$, while the commercially available LAL assay has been used by both research and clinical groups in USA, Europe and Asia [18-22]. The LAL method is more sensitive with a Lower Limit of Detection (LOD) reported as low as $3.125 \mathrm{pg} / \mathrm{ml}$ [7] compared to EIA with a reported LOD $=40$ $\mathrm{ng} / \mathrm{ml}$ [11], which limits the traditional EIA assay to settled dust and air samples collected from high-exposure environments only. Due to its high sensitivity, the LAL assay has predominantly been used for the analysis of air samples $[5,18,23]$.

Both linear and branched (1-3)- $\beta$-D-glucans have been shown to enhance allergen induced airway inflammation by increasing eosinophil infiltration and specific $\operatorname{IgE}$ in guinea pigs and mice sensitized to ovalbumin [24-27]. The EIA assay described by Douwes et al. [11] reacts with both linear and branched $\beta$-D-glucans. The LAL assay was suggested to recognize both linear and branched $\beta$-D-glucans [28,29], as well as yeast $\alpha$-D-mannan, which in previous studies was viewed as a disadvantage indicating low specificity [28]. Therefore, information on the content and structure of (1-3)$\beta$-D-glucan in common indoor fungal species will help in better understanding the health effects associated with these fungi. While there are some data on the content of (1-3)- $\beta$-Dglucans in spores of the indoor fungal species of Penicillium, Aspergillus, Cladosporium and Stachybotrys [23,30], analyzed by the LAL assay, very little is known on the EIAanalyzed (1-3)- $\beta$-D-glucan of spores from different species. LAL-analyzed (1-3)- $\beta$-D-glucan is a recognized indicator of fungal biomass based on health effects and correlation with 
total fungal count [18-21]. EIA-analyzed (1-3)- $\beta$-D-glucan in settled dust has also been used as an indicator of fungal biomass $[11,16,17]$, but there are very little data on correlations between EIA-analyzed air samples and fungal counts due to the low sensitivity of EIA.

In order to better understand the health effects associated with (1-3)- $\beta$-D-glucan exposure, it is necessary to compare the commonly used assay methods. Thus, the aim of this study was to compare the specificity, sensitivity, and accuracy of LAL and EIA methods through the analysis of (1-3)$\beta$-D-glucan concentration in purified glucan standards, common indoor fungal species, and field dust samples, in order to determine which assay is a more appropriate measure of (1-3)- $\beta$-D-glucan concentration.

\section{MATERIALS AND METHODS}

\section{Laboratory Analysis of (1-3)- $\beta$-D-Glucan}

The LAL test is a quantitative direct method for the detection of (1-3)- $\beta$-D-glucans that uses (1-3)- $\beta$-D-glucan-sensitive factor G [13]. The kinetic chromogenic Limulus Amebocyte lysate assay [Glucatell ${ }^{\mathrm{TM}}$, Associates of Cape Cod, East Falmouth, MA] was performed using laboratory materials certified as glucan-free by the manufacturer (Associates of Cape Cod). From each sample, $0.5 \mathrm{ml}$ aliquot was extracted with 0.5 $\mathrm{ml}$ of $0.6 \mathrm{M} \mathrm{NaOH}$ by shaking for 1 hour at room temperature, to unwind the triple-helix structure of (1-3)- $\beta$-D-glucan and make it water-soluble. Fifty $\mu 1$ of Glucatell reagent was added to each well of serially diluted (from $1: 1$ to $1: 10^{11}$ ) extract and a control standard (1-3)- $\beta$-D-glucan (Pachyman as provided in the Glucatell kit), placed in a 96-well, flat-bottom microplate. The prepared (expected) concentrations of the glucan standards for the LAL assay were: $3.125,12.50,50$ and $100 \mathrm{pg} / \mathrm{ml}$. The optical density (OD) at $405 \mathrm{~nm}$ and the time of onset at $\mathrm{OD}=0.03$ was recorded. All samples were above the lower limit of detection (LOD) of the Glucatell assay protocol (3.125 $\mathrm{pg} / \mathrm{ml})$. The median coefficient of variation (CV) was $9 \%$ for the intra-plate variability and $27 \%$ for the inter-plate variability. Based on these values, the cumulative error was calculated to be $28 \%$.

The EIA assay was performed as described by Douwes $e t$ $a l$. [11], except that the source of the antibodies was different. The primary monoclonal antibody to (1-3)- $\beta$-D-glucan was mouse IgG, kappa light (Biosupplies Australia, Parkville Victoria, Australia) (31). The secondary antibody was peroxidase-conjugated affinipure sheep anti-mouse $\operatorname{IgG}(\mathrm{H}+\mathrm{L})$ (Jackson ImmunoResearch, West Grove, PA). The sample extraction was accomplished by heat extraction in an autoclave at $120^{\circ} \mathrm{C}$ for 1 hour. The standard against which the concentrations were measured was Laminarin (as described in the protocol by Douwes et al., 1996) [11]. The prepared (expected) concentrations of the glucan standards for the EIA assay were $250,1000,2500$, and $5000 \mathrm{ng} / \mathrm{ml}$. Values below the LOD $(250 \mathrm{ng} / \mathrm{ml})$ were replaced with LOD divided by the square root of two for the data analyses. For the EIA assay, the median CV was $13.6 \%$ for the intra-plate variability and $24.2 \%$ for the inter-plate variability.

\section{Specificity, Sensitivity and Accuracy in Detecting Branched $\beta$-D-Glucans}

The specificity was defined as the ability of each test to detect the (1-3)-beta-D-glucan structure, i.e. detect the beta but not the alpha structure, and detect the (1-3)- $\beta$-D-glucan structure in both linear and branched molecules. The sensitivity was defined as the ability of each test to detect the (1-3)- $\beta$-D-glucan molecule, i.e. the lowest the (1-3)- $\beta$-Dglucan concentration that a test can detect, the greater its sensitivity. The accuracy of each test was determined by comparing the results with a known standard (Pachyman for LAL, and Laminarin for EIA). The closer the result comes to the true value, the greater the accuracy.

The following glucan standards were used to test the specificity of the LAL and EIA tests in detecting linear (Pachyman, Curdlan, and Mannan) vs branched (1-3)-Dglucans [Laminarin, Schizophyllan, MG-glucan (Macro$\operatorname{Gard}^{\mathrm{R}}$ ), Dextran, and Pullulan] (Table 2). The glucan standards were purchased from Sigma Chemical Co. (St. Louis, MO), except for Pachyman and MG-glucan, which were obtained from Megazyme International Ireland Ltd (Bray, Ireland) and Nutritional Scientific Corporation (Liberty, TX), respectively. Each standard was measured following the above stated protocol for laboratory analysis of (1-3)- $\beta$ D-glucan.

\section{Pure Fungal Cultures}

Selection of fungal species. Thirteen fungal species were selected based on their prevalence in field samples, genus variability, and public health concerns: two Cladosporium species, five Aspergillus species, Alternaria alternata, Aureobasidium pullulans, Epicoccum nigrum, Penicillium brevicompactum, Stachybotrys chartarum, and Wallemia sebi. Results from an ongoing field study [Cincinnati Childhood Allergy and Air Pollution Study (CCAAPS), see section Field Samples below] were used to identify species that are commonly found in homes. Based on Polymerase Chain Reaction (PCR) analysis of dust samples from 297 homes [32], eight fungal species that were most commonly found (>90\% frequency) were selected for this study (Table 1).

This list included three Aspergillus species. Two additional Aspergillus species were included in order to study the within species variability of (1-3)- $\beta$-D-glucan content. $P$. brevicompactum and $S$. chartarum were chosen to represent the species of medium frequency and concentration. In addition, $S$. chartarum was included due to reasons of being of health concern in indoor environments [33,34]. A non-toxic strain of $S$. chartarum was provided by the National Institute for Occupational Safety and Health (NIOSH), Morgantown, WV (research collection, No: 29-51-05; characterized as isolate JS5105) [35]. All the other species were purchased from the American Type Culture Collection (ATCC, Manassas, VA).

Preparation of spore suspension from pure fungal cultures. The freeze-dried pure fungal cultures were re-hydrated and inoculated on media by following the ATCC instructions. Spores from one-week old pure cultures were harvested from the agar surface by using micro-beads [36], and transferred into $5 \mathrm{ml}$ sterile tube, containing $0.02 \%$ Tween solution in pyrogen and glucan-free reagent water. Spore suspensions were placed in a bright-line hemocytometer (Model 3900, Hausser Scientific Company, Horsham, PA) and observed under a microscope to get an estimate of the spore concentration and to confirm the purity of spores. Serial dilutions of $10^{0}$ to $10^{-6}$ were prepared for each fungal 
Table 1. Fungal Species Selected for this Study and their Indoor Frequency and Concentration (Geometric Mean), as Measured by PCR Analysis of 297 Dust Samples

\begin{tabular}{|l|c|c|c|}
\hline \multicolumn{1}{|c|}{ Fungal Species Name } & Isolate Designation* & Frequency** & Concentration*** \\
\hline \hline Alternaria alternata & ATCC 44501 & $287(97 \%)$ & 401 \\
\hline A. chevalieri & ATCC 66451 & $291(98 \%)$ & 154 \\
\hline A. flavus & ATCC 11489 & $103(35 \%)$ & 3 \\
\hline A. penicillioides & ATCC 16910 & $277(93 \%)$ & 2 \\
\hline A. unguis & ATCC 10032 & $86(29 \%)$ & 4 \\
\hline A. versicolor & ATCC 52173 & $68(23 \%)$ & 4365 \\
\hline Aureobasidium pullulans & ATCC 58926 & $297(100 \%)$ & 1521 \\
\hline C. cladosporioides & ATCC 6721 & $297(100 \%)$ & 184 \\
\hline C. herbarum & ATCC 58927 & $293(99 \%)$ & 251 \\
\hline E. nigrum & ATCC 58875 & $293(99 \%)$ & 31 \\
\hline P. brevicompactum & ATCC 9056 & $212(71 \%)$ & 4 \\
\hline S. chartarum & 29-51-05, NIOSH & $153(52 \%)$ & 62 \\
\hline W. sebi & ATCC 42694 & $275(93 \%)$ & \\
\hline
\end{tabular}

*Isolate designation of the strain used for the (1-3)- $\beta$-D-glucan content analysis.

**Number and $\%$ of samples in which the species was detected, Cincinnati Childhood Allergy and Air Pollution Study [32].

$* * *$ Cells/mg dust.

ATCC $=$ American Type Culture Collection, Manassas, VA.

spore suspension, which was used for determining (1-3)- $\beta$ D-glucan concentration (as described above), spore concentration, and spore size. Spores were counted under a microscope as described by Adhikari et al. [37].

For determining the spore size, about $50 \mu \mathrm{l}$ of the pure spore suspension was placed on a microscopic slide, covered by a cover slide and immediately observed at $1000 \mathrm{X}$ magnification oil immersion using an optical microscope. Digital images were taken by a color video camera (SPOT advanced software, version 3.4, Diagnostic Instruments Inc, Sterling Heights, MI, USA) and the spore size of 30 spores of each species was measured from the images. Based on the average spore size (diameter for spherical; width and length for ellipsoidal spores), the spore surface area and volume were calculated. Spores of Cladosporium species, S. chartarum, A. alternata and A. pullulans are ellipsoidal, and therefore, equations for a prolate ellipsoid were used. The surface area and volume for the spores of the other fungal species were calculated according to the formulas for a sphere.

The (1-3)- $\beta$-D-glucan results of both assays were converted from $\mathrm{pg} / \mathrm{ml}$ to $\mathrm{pg} /$ spore for the spore suspensions. After measuring the spore size and calculating the spore surface area and volume, the results were also converted to $\mathrm{pg} / \mu \mathrm{m}^{2}$ and $\mathrm{pg} / \mu \mathrm{m}^{3}$.

\section{Field Samples}

Field samples were obtained through the CCAAPS project. The CCAAPS is a prospective birth cohort study aimed at investigating the role of aeroallergens and diesel exhaust particles in the development of atopy and atopic respiratory disorders [38]. When participating infants reached an average age of 8 months, families were visited at their homes and dust samples were vacuumed from the floor of baby's primary activity room [39]. The home dust sample was sieved
(355 $\mu \mathrm{m}$ sieve), and the fine dust was divided into subsamples and stored at $-20^{\circ} \mathrm{C}$ before analyses.

Sub-samples of $50 \mathrm{mg}$ and $40 \mathrm{mg}$ were analyzed for (1$3)-\beta$-D-glucan concentration by the LAL $(n=297)$ and EIA assays $(n=70)$, respectively. Results of the (1-3)- $\beta$-D-glucan concentration in dust samples were reported as $\mu \mathrm{g} / \mathrm{g}$ of dust and $\mu \mathrm{g} / \mathrm{m}^{2}$ of floor area.

\section{Data Analyses}

The (1-3)- $\beta$-D-glucan content of fungal spores, as well as their respective spore sizes, surface areas and volumes, were not normally distributed even after log-transformation. The correlations with and between the LAL- and EIA-analyzed (1-3)- $\beta$-D-glucan contents of fungal spores were tested with the non-parametric Spearman correlation, and the difference of means with the Wilcoxon statistics.

(1-3)- $\beta$-D-glucan concentration in 297 dust samples collected from the CCAAPS homes followed the normal Gaussian distribution after log-transformation. The EIA-analyzed (1-3)- $\beta$-D-glucan concentration in indoor dust samples did not follow the Gaussian distribution even after logtransformation. Thus non-parametric analyses were used to test for correlation and difference between the LAL- and EIA-analyzed (1-3)- $\beta$-D-glucan concentrations in dust samples.

\section{RESULTS}

\section{Specificity and Accuracy of LAL and EIA in Measuring Glucans of Different Linkage and Branching}

The reactivity of LAL and EIA assays to $\alpha$ - and $\beta$ glucans of various degree of branching are shown in Fig. (1). As the LAL assay (Fig. 1A) is a kinetic assay measuring the onset of time at $\mathrm{OD}=0.03$, the later the reaction occurs (mean onset time), the lower the specificity for the particular 
purified glucan at that concentration in comparison to the other glucan standards. In the endpoint EIA assay, the best curve is curvilinear, with a rapid straight decrease in the absorbance units with the increase of the concentration until saturation of the curve is reached (Fig. 1B). As seen in Fig. (1), both LAL and EIA assay were specific to linear (1-3)- $\beta$ D-glucans (Curdlan and Pachyman: change in concentration is reflected by change in mean onset time/absorbance units) and non-reactive to $\alpha$-glucans (Mannan, Dextran, and Pullulan: presented by straight horizontal lines, i.e. no change in detection with increase in concentration). The reactivity of the LAL assay slightly decreased with the increase in the degree of branching (Fig. 1A). Although the EIA assay was also specific in recognizing close to linear structures (Laminarin), its specificity to branched structures was negligible [(Schizophylan, branched (1-3)(1-6)- $\beta$-D-glucan)] (Fig. 1B).

The measured concentrations for glucan standards were calculated based on a standard curve of Pachyman for the LAL assay and Laminarin for the EIA assay. These values, expressed as \% of the expected concentrations, are presented in Table 2. For each standard concentration the LAL was more accurate in measuring concentrations of (1-3)- $\beta$-Dglucan standards than the EIA as demonstrated by the narrower range and the smaller median value of the \% expected concentration (Table 2).

\section{Sensitivity of LAL and EIA in Measuring (1-3)- $\beta$-D- Glucan in Pure Fungal Spores}

The spore size, spore surface area, and spore volume of the thirteen fungal species analyzed are provided in Table $\mathbf{3}$. Among the fungal species, E. nigrum had the largest spore size, and thus the biggest surface area and volume. The Aspergillus species were small in size, and Aspergillus versicolor was the smallest among them. The measured spore sizes and surface areas were within the range reported earlier $[30,40,41]$.

Based on the spore characteristics reported in Table $\mathbf{3}$, we compared the sensitivity of the two assays (i.e., ability to detect lower concentrations of (1-3)- $\beta$-D-glucan) by calculating the (1-3)- $\beta$-D-glucan content per spore, spore surface
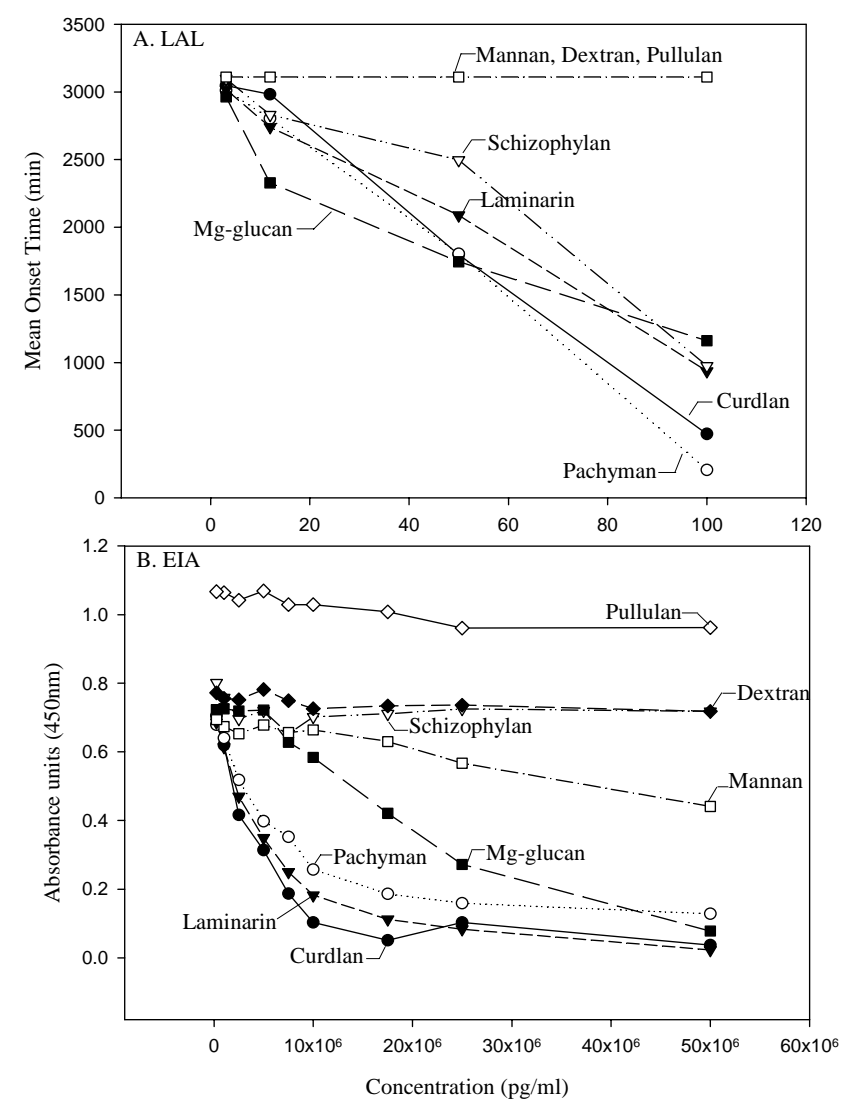

Fig. (1). Comparison of eight purified glucans and their reactivity as measured by (A) the kinetic LAL and (B) endpoint EIA assays.

area, and spore volume (Tables $\mathbf{4 A}$ and $\mathbf{4 B}$ ). Although $E$. nigrum was the species of greatest (1-3)- $\beta$-D-glucan content per spore ( $241 \mathrm{pg} /$ spore), this was mainly due to having also the largest spore size $(28 \mu \mathrm{m})$. The biomass-normalized (13 )- $\beta$-D-glucan content (pg per spore surface area and pg per spore volume) measured by both assays was within similar range (LAL: 0.03 to $146.33 * 10^{-3} \mathrm{pg} / \mu \mathrm{m}^{2}, 0.22-240.54 * 10^{-3}$ $\mathrm{pg} / \mu \mathrm{m}^{3}$; EIA: $0.04-197.00 * 10^{-3} \mathrm{pg} / \mu \mathrm{m}^{2}, 0.03-300 * 10^{-3}$ $\left.\mathrm{pg} / \mu \mathrm{m}^{3}\right)$. The LAL assay determined C. herbarum, followed

Table 2. Comparison of Eight Purified Glucans and their Relative Reactivity as Measured by the LAL and EIA Assays*

\begin{tabular}{|c|c|c|c|c|c|}
\hline \multirow{3}{*}{ Glucan } & \multirow{3}{*}{ Linkages } & \multicolumn{4}{|c|}{$\%$ of the Expected Concentration ${ }^{* *}$} \\
\hline & & \multicolumn{2}{|c|}{ LAL } & \multicolumn{2}{|c|}{ EIA } \\
\hline & & Range & Median Value & Range & Median Value \\
\hline Curdlan & Linear (1-3)- $\beta$-D-glucan & $43-100$ & 96.4 & $95-150$ & 97.0 \\
\hline Pachyman & Linear (1-3)- $\beta$-D-glucan & $97-118$ & 104.8 & $56-94$ & 73.7 \\
\hline Laminarin & $(1-3)(1-6)-\beta$-D-glucan (some branching) & $78-118$ & 99.3 & $71-120$ & 98.2 \\
\hline Schizophylan & $(1-3)(1-6)-\beta$-D-glucan (33\% branching) & $47-118$ & 84.7 & \multicolumn{2}{|c|}{ No response } \\
\hline MG-glucan & Branched (1-3)(1-6)- $\beta$-D-glucan extract from baker's yeast & $74-240$ & 96.0 & \multicolumn{2}{|c|}{ No response } \\
\hline Mannan & Linear (1-3)- $\alpha$-D-Mannose & \multicolumn{2}{|c|}{ No response } & \multicolumn{2}{|c|}{ No response } \\
\hline Dextran & Branched (1-3)(1-6)- $\alpha$-D-glucose & \multicolumn{2}{|c|}{ No response } & \multicolumn{2}{|c|}{ No response } \\
\hline Pullulan & Branched (1-3)(1-4)- $\alpha$-D-glucose & \multicolumn{2}{|c|}{ No response } & \multicolumn{2}{|c|}{ No response } \\
\hline
\end{tabular}

"The standard against which the concentrations are measured is Pachyman for the LAL assay, and Laminarin for the EIA assay.

${ }^{* * *}$ The prepared (expected) concentrations of the glucan standards for the LAL assay were: $3.125,12.50,50$, and $100 \mathrm{pg} / \mathrm{ml}$. The prepared (expected) concentrations of the glucan standards for the EIA assay were $250,1000,2500$, and $5000 \mathrm{ng} / \mathrm{ml}$. The measured values were expressed as \% of the expected concentrations. 
Table 3. Characteristics of Fungal Species Grown in Pure Fungal Cultures - Spore Size ( $\mu \mathrm{m})$, Spore Surface Area $\left(\mu \mathrm{m}^{2}\right)$ and Spore Volume $\left(\mu \mathrm{m}^{3}\right)^{*}$

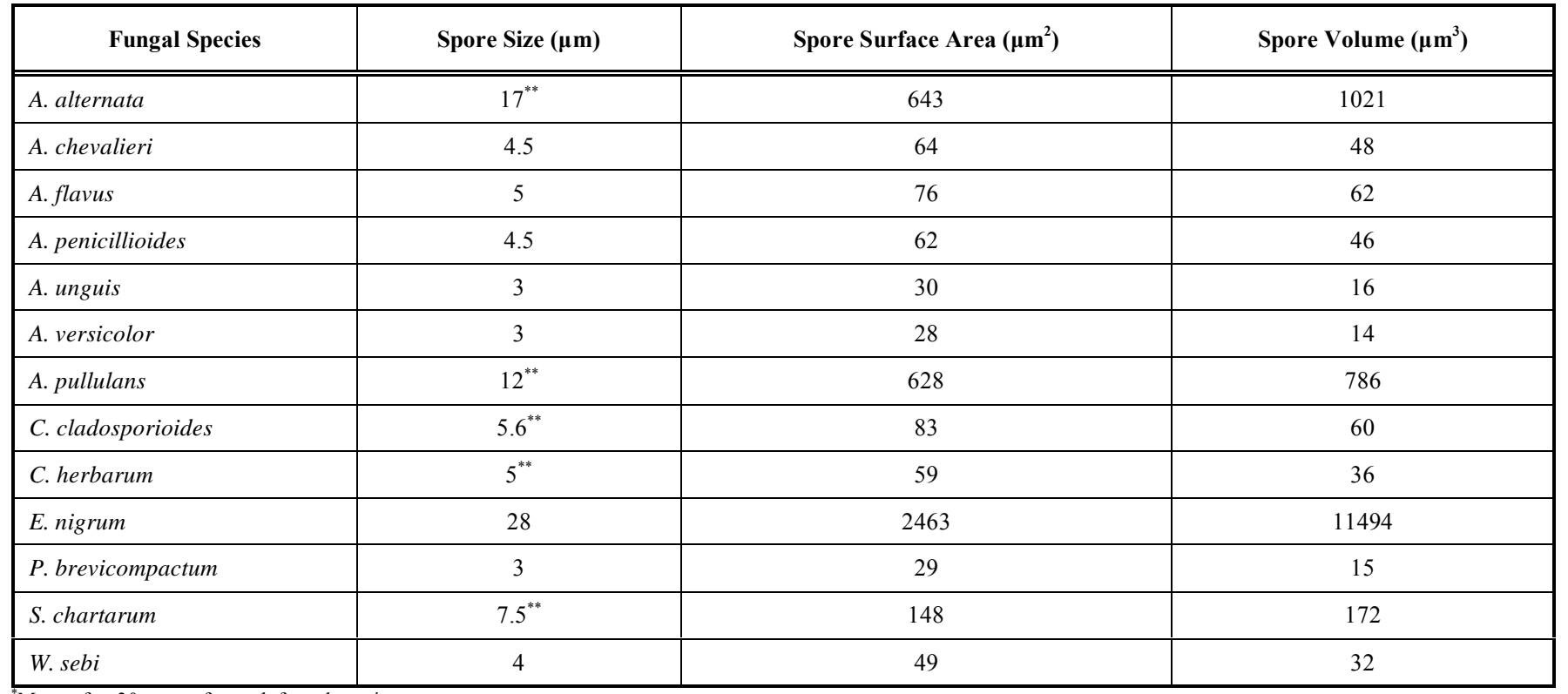

${ }_{* *}^{*}$ Mean of $\mathrm{n}=30$ spores for each fungal species.

${ }^{* *}$ Geometric mean of width and length for ellipsoidal spores.

Spores of Aspergillus species, E. nigrum, P. brevicompactum and W. sebi are spherical. Spores of A. alternata, A. pullulans, Cladosporium species, and S. chartarum are ellipsoidal.

by E. nigrum and P. brevicompactum, as the fungi of highest (1-3)- $\beta$-D-glucan content per surface area and volume. The EIA assay ranked $W$. sebi as having the highest (1-3)- $\beta$-Dglucan content, followed by E. nigrum, P. brevicompactum and $C$. cladosporioides (Table 4B). Both assays recognized Aspergillus species, A. alternata and $S$. chartarum to have the lowest (1-3)- $\beta$-D-glucan content. Three fungal species, $C$. herbarum, A. pullulans, and $S$. chartarum, were below the LOD of the EIA assay. A. alternata (1-3)- $\beta$-D-glucan content was measured only with the LAL assay $(0.03 \mathrm{pg} / \mathrm{spore}$, $\left.0.05^{*} 10^{-3} \mathrm{pg} / \mu \mathrm{m}^{2}, 0.03 * 10^{-3} \mathrm{pg} / \mu \mathrm{m}^{3}\right)$.
The data were used to analyze the variations between the 13 investigated fungal species and within 5 Aspergillus species. Both assays showed lower variation of (1-3)- $\beta$-Dglucan content within the 5 Aspergillus species than between the 13 fungal species (LAL: Coefficients of variation $=45 \%$ and $58 \%$, respectively; EIA: Coefficients of variation $=22 \%$ and $42 \%$, respectively).

No correlation was found between LAL- or EIAanalyzed (1-3)- $\beta$-D-glucan content (pg/spore) and spore size, spore surface area, or volume $(p>0.20)$. Furthermore, no

Table 4A. Average $\uparrow$ (1-3)- $\beta$-D-glucan Contents of Twelve Common Indoor Fungal Species as Measured by the LAL Assay

\begin{tabular}{|l|c|c|c|}
\hline \multicolumn{1}{|c|}{ Fungal Species } & pg/Spore & pg/Spore Surface Area* & pg/Spore Volume** \\
\hline \hline A. chevalieri & 0.22 & 3.46 & 4.61 \\
\hline A. flavus & 0.03 & 0.39 & 0.48 \\
\hline A. penicillioides & 0.01 & 0.16 & 0.22 \\
\hline A. unguis & 0.005 & 0.16 & 0.32 \\
\hline A. versicolor & 0.03 & 0.91 & 1.84 \\
\hline A. pullulans & 3.76 & 5.98 & 4.78 \\
\hline C. cladosporioides & 0.25 & 3.00 & 4.19 \\
\hline C. herbarum & 8.66 & 146.33 & 240.54 \\
\hline E. nigrum & 241.57 & 98.08 & 21.02 \\
\hline P. brevicompactum & 0.21 & 7.02 & 13.81 \\
\hline S. chartarum & 0.004 & 0.03 & 0.33 \\
\hline W. sebi & 0.12 & 2.40 & 3.72 \\
\hline
\end{tabular}

$* \mathrm{pg} / \mu \mathrm{m}^{2} \times 10^{-3}$.

$* * \mathrm{pg} / \mathrm{\mu m}^{3} \times 10^{-3}$.

$\dagger(1-3)-\beta$-D-glucan content is an average of $4-6$ experiments, $C V=27 \%$. 
Table 4B. Average $\dagger$ (1-3)- $\beta$-D-Glucan Contents of Twelve Common Indoor Fungal Species as Measured by the EIA Assay

\begin{tabular}{|c|c|c|c|}
\hline Fungal Species & pg/Spore & pg/Spore Surface Area* & pg/Spore Volume*** \\
\hline A. chevalieri & 0.24 & 3.81 & 5.08 \\
\hline A. flavus & 0.10 & 1.34 & 1.64 \\
\hline A. penicillioides & 0.13 & 2.06 & 2.78 \\
\hline A. unguis & 0.02 & 0.57 & 1.10 \\
\hline A. versicolor & 0.08 & 3.01 & 6.10 \\
\hline A. pullulans ${ }^{* * * *}$ & $(0.02)$ & $(0.04)$ & $(0.03)$ \\
\hline C. cladosporioides & 7.20 & 86.30 & 120.55 \\
\hline C. herbarum ${ }^{* * * *}$ & $(0.06)$ & $(1.01)$ & $(1.72)$ \\
\hline E. nigrum & 379.97 & 153.25 & 32.72 \\
\hline P. brevicompactum & 3.39 & 116.10 & 228.39 \\
\hline S. chartarum $^{* * *}$ & $(0.58)$ & $(3.94)$ & $(3.40)$ \\
\hline W. sebi & 9.68 & 197.00 & 300.01 \\
\hline
\end{tabular}

$* \mathrm{pg} / \mu \mathrm{m}^{2} \times 10^{-3}$.

$* * \mathrm{pg} / \mu \mathrm{m}^{3} \times 10^{-3}$.

${ }^{* * *}$ The value for this fungal (1-3)- $\beta$-D-glucan concentration was below the lower detection limit of the EIA assay ( $\left.250 \mathrm{ng} / \mathrm{ml}\right)$. These values were replaced with LOD divided by the square root of two.

$\dagger(1-3)-\beta$-D-glucan content is an average of 4-6 experiments, $C V=24 \%$

correlation was observed between LAL-analyzed and EIAanalyzed (1-3)- $\beta$-D-glucan content per spore.

\section{Comparison of LAL vs EIA Analyzed (1-3)- $\beta$-D-Glucan in Dust Samples}

The EIA-measured (1-3)- $\beta$-D-glucan levels [geometric mean $(\mathrm{GM})=15,998 \mu \mathrm{g} / \mathrm{g}$ and $\left.3,775 \mu \mathrm{g} / \mathrm{m}^{2}\right]$ in dust samples were higher than the LAL-measured $(\mathrm{GM}=40 \mu \mathrm{g} / \mathrm{g}$ and 9 $\left.\mu \mathrm{g} / \mathrm{m}^{2}\right)$. This difference was significant in both units $(\mu \mathrm{g} / \mathrm{g}$ : $\mathrm{z}$-value $=-7.21, \mathrm{p}<0.001 ; \mu \mathrm{g} / \mathrm{m}^{2}: \mathrm{z}$-value $\left.=-7.26, \mathrm{p}<0.001\right)$. However, the variability in (1-3)- $\beta$-D-glucan levels was greater as measured by the LAL [Geometric standard deviation $(\mathrm{GSD})=1.70$ and 2.00] than the EIA assay $(\mathrm{GSD}=1.45$ and 1.81). There was no correlation between LAL- and EIAanalyzed (1-3)- $\beta$-D-glucan in dust samples, when concentration was expressed per gram of dust (Fig. 2), but moderate and statistically significant when expressed per square meter of floor area (Fig. 3).

\section{DISCUSSION}

The utility of the LAL assay in measuring serum fungal (1-3)- $\beta$-D-glucans has been evaluated in numerous laboratory and clinical studies and the assay is currently routinely used in Japan and Europe for the detection of invasive fungal infections [42-44]. The EIA assay is not commercially available, and is not generally performed in most clinical laboratories. In addition, less data are available on the utility of LAL and EIA assays in the analysis of fungal (1-3)- $\beta$-Dglucan concentration in environmental samples $[4,5,45,46]$. Thus, the current study is the first one to directly compare the specificity, sensitivity, and accuracy of LAL versus EIA assays in detecting fungal (1-3)- $\beta$-D-glucans.

The current study confirmed that the LAL assay recognized both linear and branched (1-3)- $\beta$-D-glucans, as previously reported by Tanaka et al. [28] and Thorne et al. [29]. This study also confirmed that the EIA immunoassay reacts with linear (1-3)- $\beta$-D-glucans, as earlier reported by Douwes

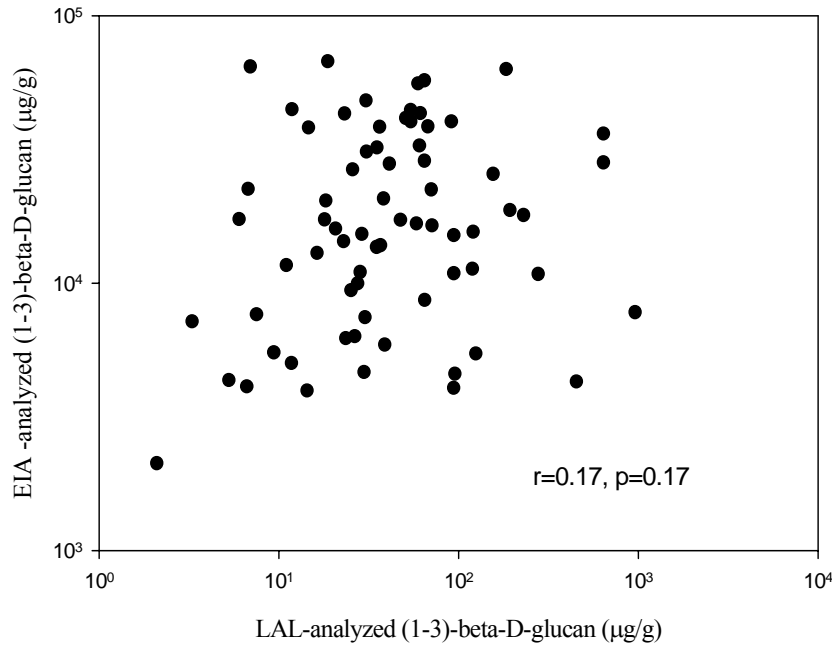

Fig. (2). LAL vs EIA-analyzed (1-3)- $\beta$-D-glucan in 70 dust samples in $\mu \mathrm{g} / \mathrm{g}$.

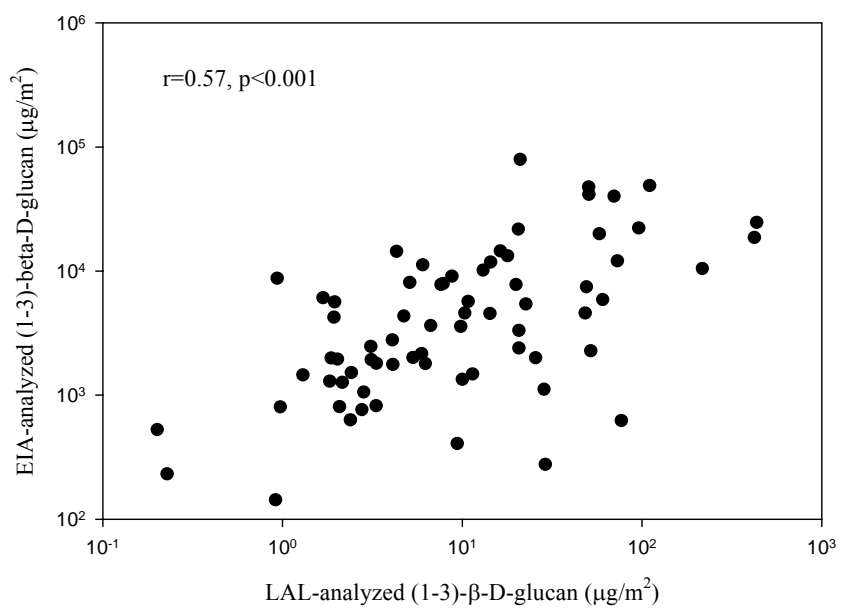

Fig. (3). LAL vs EIA-analyzed (1-3)- $\beta$-D-glucan in 70 dust samples in $\mu \mathrm{g} / \mathrm{m}^{2}$. 
et al. [11]. New modifications of the ELISA assay are highly specific to branched (1-3)(1-6)- $\beta$-D-glucans only $[14,15]$. It has been reported that both linear and branched type $\beta$-Dglucans are ubiquitous in the cell wall of fungi [47], and both types of $\beta$-D-glucans are important for in vivo priming of macrophages [48], as well as potentiate allergic reactions with the elevation of $\operatorname{IgE}$ in mice and guinea pigs [24-27]. Thus, the measurement of both linear and branched $\beta$-Dglucans appears to be important. From this perspective, the LAL and inhibition EIA assays seem to be more desirable to use for fungal exposure assessment than the new ELISA methods. However, the LAL assay showed greater sensitivity and specificity $(\mathrm{LOD}=3.125 \mathrm{pg} / \mathrm{ml}$, detected both linear and branched $\beta$-D-glucans with comparable sensitivity) in comparison to the EIA assay ( $\mathrm{LOD}=250 \mathrm{ng} / \mathrm{ml}$, detected preferably the linear (1-3)- $\beta$-D-glucans). In addition, the LAL was more accurate in measuring concentrations of (1$3)-\beta$-D-glucan standards than the EIA as demonstrated by the smaller difference between measured and expected concentrations.

A major disadvantage of the EIA assay is its low sensitivity. Thus, the low content of EIA-reactive (1-3)- $\beta$-Dglucan antigens in the pure fungal suspensions of $C$. herbarum, A. pullulans and $S$. chartarum is a limitation of the study. This difference in the detection sensitivity and specificity between assays may explain the difference of (1-3)- $\beta$ $D$-glucan content in the same fungus species when determined by LAL vs EIA. This may also explain the lack of correlation between LAL- $v s$ EIA-analyzed (1-3)- $\beta$-D-glucan content of fungal spores.

Previous studies that have used the LAL assay on serum and culture supernatants of clinical fungal isolates have shown that the (1-3)- $\beta$-D-glucan content of different fungal species varies widely $[42,43]$. This study also showed a wide range of (1-3)- $\beta$-D-glucan content between 13 species from 7 genera and within Aspergillus genus, as demonstrated by the large coefficients of variation measured both with the LAL and EIA.

In this study, Aspergillus species, A. alternata and $S$. chartarum had the lowest (1-3)- $\beta$-D-glucan contents. Although no previous study reported the LAL-analyzed (1-3)$\beta$-D-glucan content of A. alternata, studies have isolated elicitor-active components from A. alternata 102 that consisted almost solely of (1-3)(1-6)- $\beta$-D-glucan [49]. Fogelmark and Rylander have reported that the Stachybotrys atra (=S. chartarum) (median $3.9 \mathrm{pg} / \mathrm{spore}$, range 0.9-39.3 $\mathrm{pg} / \mathrm{spore}$ ) has 1,000 times higher LAL-analyzed (1-3)- $\beta$-Dglucan than Aspergillus fumigatus (median: $0.11 \mathrm{pg} / \mathrm{spore}$, range $0.008-0.7 \mathrm{pg} /$ spore) [23]. The much lower (1-3)- $\beta$-Dglucan content in the Stachybotrys spores in the present study may be due to the fact that it was a non-toxic strain. Though, there is very little information on the association between (1-3)- $\beta$-D-glucan content and fungal toxicity, low (1-3)- $\beta$-D-glucan content is known to be associated with lower pathogenicity [50,51]. Also, growth conditions, and thus growth media, can affect the content of fungal (1-3)- $\beta$ D-glucans [30,52-54]. A study by Foto et al. showed that the LAL-analyzed (1-3)- $\beta$-D-glucan content in $S$. chartarum (mean $0.012 \mathrm{pg} / \mu^{2}$ ) is lower than that of A. versicolor (mean $0.022 \mathrm{pg} / \mu^{2}$ ) and C. cladosporioides (mean 0.060 $\mathrm{pg} / \mu \mathrm{m}^{2}$ ), all grown on $2 \%$ malt extract agar [30]. Although the (1-3)- $\beta$-D-glucan contents measured by the LAL in the present study are higher than those reported by Foto et al. [30], the same trend among species was observed.

The rank order of EIA analyzed fungal (1-3)- $\beta$-D-glucan content in the present study was different from what was reported for a mixture of fungal mycelia and spores assayed by the monoclonal IgM ELISA [15]. Aspergillus flavus isolated from stored urine and Aspergillus ochraceus isolated from outdoor air samples had higher (1-3)- $\beta$-D-glucan content (measured as ng per $\mathrm{mg}$ of cultured fungal isolates) than Cladosporium spp. isolated from bedroom air and Wallemia spp. isolated from outdoor air. This may be due to the different sources from which species were isolated and inclusion of both spores and mycelia, which may have different (1-3)$\beta$-D-glucan content per cell. Furthermore, the IgM ELISA measures the content of branched (1-3)(1-6)- $\beta$-D-glucan only, and thus may underestimate the (1-3)- $\beta$-D-glucan content of Cladosporium spp., as they have been reported to contain predominantly linear glucans $[55,56]$.

This appears to be the first report on LAL-analyzed (1$3)-\beta-D$-glucan concentration in a large number of dust samples. The LAL-analyzed dust (1-3)- $\beta$-D-glucan levels measured in this study were lower than those measured in Canadian homes $(\mathrm{n}=28)$ of asthmatic children $(\mathrm{GM}=172 \mu \mathrm{g} / \mathrm{g}$ and $\left.\mathrm{GM}=160 \mu \mathrm{g} / \mathrm{m}^{2}\right)$ [45] and homes perceived as having satisfactory indoor quality $(\mathrm{n}=20) \quad\left(\right.$ median $\left.=230 \mu \mathrm{g} / \mathrm{m}^{2}\right)$ [46]. These differences may be due to different geography and/or heating [16] (in colder climate) in the Canadian homes. The EIA assay used in this study measured much higher indoor dust (1-3)- $\beta$-D-glucan (GM=15,998 $\mu \mathrm{g} / \mathrm{g}$ and $3,775 \mu \mathrm{g} / \mathrm{m}^{2}$ ) than those reported in other studies. However, difference in sampling protocols (e.g., mesh size for sieving), seasonal and geographical variations can contribute to this difference. A wide range in the levels of EIA-analyzed dust (1-3)- $\beta$-Dglucan in European Union countries was reported - from $35.1 \mu \mathrm{g} / \mathrm{g} \quad(\mathrm{GSD}=1.80, \mathrm{n}=20)$ to $2,959 \mu \mathrm{g} / \mathrm{g} \quad(\mathrm{GSD}=1.94$, $\mathrm{n}=441$ ) $[15,17,57,58]$, and from $90 \mu \mathrm{g} / \mathrm{m}^{2}$ (no GSD reported, $\mathrm{n}=508)$ to $1,197 \mu \mathrm{g} / \mathrm{m}^{2}(\mathrm{GSD}=2.5, \mathrm{n}=395)[6,17,58,59]$. ( 1 $3)-\beta-D$-glucan levels can vary between seasons; Chew et al. [16] observed $\mathrm{GM}=1,551 \mu \mathrm{g} / \mathrm{g}(\mathrm{GSD}=2.4, \mathrm{n}=26)$ in spring and $\mathrm{GM}=2,219 \mu \mathrm{g} / \mathrm{g}(\mathrm{GSD}=2.7)$ in fall. In addition, the source of primary and secondary antibodies used is also different between the EIA assay used in this study $v s$ in European studies, and thus data may not be directly comparable.

Although the (1-3)- $\beta$-D-glucan content of pure fungal cultures showed a similar rank of order whether measured by the LAL or EIA assay, there was about 1,000 times difference in the (1-3)- $\beta$-D-glucan concentration in dust samples when analyzed by the LAL $v$ s the EIA assay. Previous studies show that (1-3)- $\beta$-D-glucan concentrations do not consistently correlate with total culturable fungal spore counts $[17,21,60]$. (1-3)- $\beta$-D-glucan concentrations in the environment more likely reflect exposure from multiple environmental sources of (1-3)- $\beta$-D-glucan, including fungi, pollen, plants and their fragments [30,61]. Since, these various sources may also contain other sugars, some interference of these (inhibition or enhancement) with the assay results may be expected [62,63]. In addition, these assays differ in measurement of $\beta$-D-glucans of different branching and conformation, which may lead to the orders of magnitude difference between the LAL and EIA assay measurements. It 
seems that a combination of both assays can provide better perspective on the content and types of (1-3)- $\beta$-D-glucan exposure.

This and previous studies [30] have shown that (1-3)- $\beta$ D-glucan content varies between fungal species, and this may lead to variance of health outcomes by fungal genera [64]. For example, in the CCAAPS cohort, we have found an inverse association between the health outcomes and some fungal types [the concentration of airborne Cladosporium and SPT $(+)$ to any allergen $(P<0.05)$, and Cladosporium and SPT $(+)$ to aeroallergens $(P<0.05)$ ], but positive associations with some other fungal types [Penicillium/Aspergillus and SPT $(+)$ to any allergen $(P<0.01)$ and between Alternaria and SPT $(+)$ to any allergen $(P<0.01)$ ] [64]. Previous studies utilizing the EIA assay have shown stronger association between dust (1-3)- $\beta$-D-glucan exposures and the health outcome (peak flow variability) in per square meter units than per gram units [65], or no association at all (asthma and wheeze) per gram unit [6]. The current study showed that LAL and EIA (1-3)- $\beta$-D-glucan exposures per square meter correlate significantly, but not when expressed per gram of floor dust. Therefore, comparison of published LAL and EIA data per gram of dust is not plausible. It seems (1-3)- $\beta$-D-glucan may be an independent measure of biologically active exposure and measuring exposures per square meter can provide a better understanding of health outcomes, as well as a possibility for comparison of (1-3)- $\beta$-D-glucan exposures measured by these two different assays.

In conclusion, the LAL assay was shown to be more specific, sensitive, and accurate in detecting both linear and branched $\beta$-D-glucans. Although the (1-3)- $\beta$-D-glucan concentration in field samples measured by the LAL and EIA assay correlated, data should be analyzed with caution, as assays measure different aspects of the (1-3)- $\beta$-D-glucan structure and give different weight to different fungal species.

\section{ACKNOWLEDGEMENTS}

This study was supported by National Institute of Environmental Health Sciences (NIEHS) grant ES11170 and the National Institute for Occupational Safety and Health (NIOSH) Pilot Research Project Training Program of the University of Cincinnati Education and Research Center Grant T42/OH008432. Yulia Iossifova received the Strategic Training in Allergy Research (ST*AR) Award to present these results at the Annual Meeting of the American Academy of Allergy, Asthma and Immunology.

\section{REFERENCES}

[1] Curtis L, Lieberman A, Stark M, Rea W, Vetter M. Adverse health effects of indoor molds. J Nutr Environ Med 2004; 14: 261-274.

[2] Johanning E. Indoor moisture and mold related health problems. Eur Ann Allergy Clin Immunol 2004; 36: 182-185.

[3] Rylander R. Symptoms and mechanisms: inflammation of the lung. Am J Ind Med 1994; 25: 19-23.

[4] Douwes J. 1-3- $\beta$-D-glucans and respiratory health: a review of the scientific evidence. Indoor Air 2005; 15: 160-169.

[5] Rylander R, Lin R. (1-->3)-beta-D-glucan - relationship to indoor air-related symptoms, allergy and asthma. Toxicology 2000; 152: 47-52.

[6] Douwes J, van Strien R, Doekes G, et al. Does early indoor microbial exposure reduce the risk of asthma? The Prevention and Inci- dence of Asthma and Mite Allergy birth cohort study. J Allergy Clin Immunol 2006; 117: 1067-1073.

[7] Iossifova Y, Reponen T, Bernstein D, et al. House dust (1-3)- $\beta$-dglucan and wheezing in infants. Allergy 2007; 62: 504-513.

Gehring U, Heinrich J, Hoek G, et al. Bacteria and mould components in house dust and children's allergic sensitisation. Eur Respir J 2007; 29: 1144-53.

[9] von Mutius E, Braun-Fahrlander C, Schierl R, et al. Exposure to endotoxin or other bacterial components might protect against the development of atopy. Clin Exp Allergy 2000; 30: 1230-1234.

[10] Schram-Bijkerk D, Doekes G, Douwes J, et al. Bacterial and fungal agents in house dust and wheeze in children: the PARSIFAL study. Clin Exp Allergy 2005; 35: 1272-1278.

[11] Douwes J, Doekes G, Montijn R, Heederik D, Brunekreef B Measurement of $\beta(1,3)$-glucans in occupational and home environments with an inhibition enzyme immunoassay. Appl Environ Microbiol 1996; 62: 3176-3182.

[12] Douwes J, Thorne P, Pearce N, Heederick D. Bioaerosol health effects and exposure assessment: progress and prospects. Ann Occup Hyg 2003; 47: 187-200.

[13] Obayashi $\mathrm{T}$, Tamura $\mathrm{H}$, Tanaka $\mathrm{S}$, et al. A new chromogenic endotoxin-specific assay using recombined limulus coagulation enzymes and its clinical applications. Clin Chim Acta 1985; 149: 55-65.

[14] Adachi Y, Ohno N, Yadomae T. Preparation and antigen specificity of an anti-(1-->3)-beta-D-glucan antibody. Biol Pharm Bul 1994; 17: $1508-1512$

[15] Milton D, Alwis U, Fisette L, Muilenberg M. Enzyme-linked immunosorbent assay specific for $(1 \rightarrow 6)$ branched, (13)- $\beta$-D-glucan detection in environmental samples. Appl Environ Microbiol 2001; 67: $5420-5424$

[16] Chew G, Douwes J, Doekes G, et al. Fungal extracellular polysaccharides, $\beta(1,3)$-glucans and culturable fungi in repeated sampling of house dust. Indoor Air 2001; 11: 171-178.

[17] Gehring U, Douwes J, Doekes G, et al. $\beta(1,3)$-glucan in house dust of German homes: Housing characteristics, occupant behavior, and relations with endotoxins, allergens and molds. Environ Health Perspect 2001; 109: 139-144.

[18] Rylander R, Thorn J, Attefors R. Airways inflammation among workers in a paper industry. Eur Respir J 1999; 13: 1151-1157.

[19] Alwis K, Mandryk J, Hocking A. Exposure to biohazards in wood dust: bacteria, fungi, endotoxins, and (1-3)- $\beta$-D-glucans. Appl Occup Environ Hyg 1999; 14: 598-608.

[20] Mandryk J, Alwis K, Hocking A. Effects of personal exposure on pulmonary function and work-related symptoms among sawmill workers. Ann Occup Hyg 2000; 44: 281-289.

[21] Wan GH, Li CS. Indoor endotoxin and glucan in association with airway inflammation and systemic symptoms. Arch Environ Health 1999; 54: 72-179.

[22] Foto M, Vrijmoed L, Miller J, Ruest K, Lawton M, Dales R. A comparison of airborne ergosterol, glucan and Air-O-Cell data in relation to physical assessments of mold damage and some other parameters. Indoor Air 2005; 15: 257-266.

[23] Fogelmark B, Rylander R. ( $1 \rightarrow 3)-\beta$-D-glucan in some indoor air fungi. Indoor Built Environ 1997; 6: 291-294.

[24] Rylander R, Holt PG. (1->3)-beta-D-glucan and endotoxin modulate immune response to inhaled allergen. Mediators Inflamm 1998; 7: 105-110.

[25] Ormstad H, Groeng EC, Lovik M, Hetland G. The fungal cell wall component beta-1,3-glucan has an adjuvant effect on the allergic response to ovalbumin in mice. J Toxicol Environ Health 2000; 61: 55-67.

[26] Wan GH, Li CS, Guo SP, Rylander R, Lin RH. An airborne moldderived product, $\beta$-1,3-d-glucan potentiates airway allergic responses. Eur J Immunol 1999; 29: 2491-2497.

[27] Instanes C, Ormstad H, Rydjord B, Wiker HG, Hetland G. Mould extracts increase the allergic response to ovalbumin in mice. Clin Exp Allergy 2004; 34: 1634-1641.

[28] Tanaka S, Aketagawa J, Takahashi S, Shibata Y, Tsumuraya Y, Hashimoto Y. Activation of a limulus coagulation factor G by (13)-B-D-glucans. Carbohydr Res 1991; 218: 167-174.

[29] Thorne P, Duchaine C, Douwes J, et al. Working group report 4 exposure assessment for biological agents. Am J Ind Med 2004; 46 : 419-422.

[30] Foto M, Plett J, Berghout J, Miller J. Modification of the Limulus amebocyte lysate assay for the analysis of glucan in indoor environments. Anal Bioanal Chem 2004; 379: 156-62. 
[31] Gianinazzi-Pearson V, Lemoine M, Arnould C, et al. Localization of $\beta(1 \rightarrow 3)$ Glucans in Spore and Hyphal Walls of Fungi in the Glomales. Mycologia 1994; 86: 478-485.

[32] Vesper S, McKinstry C, Haugland R, et al. Relative moldiness index as predictor of childhood respiratory illness. J Expo Sci Environ Epidemiol 2007; 17: 88-94.

[33] Hossain M, Ahmed M, Ghannoum M. Attributes of Stachybotrys chartarum and its association with human disease. J Allergy Clin Immunol 2004; 113: 200-208.

[34] Lai K. Hazard identification, dose-response and environmental characteristics of stachybotryotoxins and other health-related products from Stachybotrys. Environ Technol 2006; 27: 329-335.

[35] Jarvis B, Sorenson W, Hintikka E, et al. Study of toxin production by isolates of Stachybotrys chartarum and Memnoniella echinata isolated during a study of pulmonary hemosiderosis in infants. Appl Environ Microb 1998; 64: 3620-3625.

[36] Schmechel D, Simpson J, Beezhold D, Lewis D. The development of species-specific immunodiagnostics for Stachybotrys chartarum: The role of cross-reactivity. J Immunol Methods 2006; 309: 150159.

[37] Adhikari A, Martuzevicius D, Reponen T, et al. Performance of the button personal inhalable sampler for the measurement of outdoor aeroallergens. Atmos Environ 2003; 37: 4723-4733.

[38] Ryan P, LeMasters G, Biagini J, et al. Is it traffic type, volume, or distance? Wheezing in infants living near truck and bus traffic. J Allergy Clin Immunol 2005; 116: 279-84.

[39] Cho SH, Reponen T, LeMasters G, et al. Mold damage in homes and wheezing in infants. Ann Allergy Asthma Immunol 2006; 27: $1-7$.

[40] Bauer H, Kasper-Giebl A, Zibuschka F, Hitzenberger R, Kraus G, Puxbaum H. Determination of the carbon content of airborne fungal spores. Anal Chem 2002; 74: 91-95.

[41] Reponen T, Grinshpun S, Conwell K, Wiest J, Anderson M. Aerodynamic versus physical size of spores: measurement and implication for respiratory deposition. Grana 2001; 40: 119-125.

[42] Odabasi Z, Paetznick V, Rodriguez J, Chen E, Mcginnis M, Ostrosky-Zeichner L. Differences in beta-glucan levels in culture supernatants of a variety of fungi. Med Mycol 2006; 44: 267-272.

[43] Yuasa K, Goto H, Iguchi M, Okamura T, Ieki R. Evaluation of the diagnostic value of the measurement of (1-->3)-beta-D-glucan in patients with pulmonary aspergillosis. Respiration 1996; 63: 78-83.

[44] Stevens DA. Diagnosis of fungal infections: Current status. J Antimicrob Chemother 2002; 49: 11-19.

[45] Berghout J, Miller J, Mazerolle R, et al. Indoor environmental quality in homes of asthmatic children on the Elsipogtog Reserve (NB), Canada. Int J Circumpolar Health 2005; 64: 77-85.

[46] Miller J, Dugandzic R, Frescura A, Salares V. Indoor- and outdoorderived contaminants in urban and rural homes in Ottawa, Ontario, Canada. J Air Waste Manag Assoc 2007; 57: 297-302.

[47] Perez P, Ribas J. Cell wall analysis. Methods 2004; 33: 245-251.

[48] Ohno N, Miura N, Chiba N, Adachi Y, Yadomae T. Comparison of the immunopharmacological activities of triple and single-helical Schizophyllan in mice. Biol Pharm Bull 1995; 18: 1242-1247.
[49] Shinya T, Menard R, Kozone I, et al. Novel $\beta-1,3-1,6$-oligoglucan elicitor from Alternaria alternata 102 for defense responses in tobacco. FEBS J 2006; 273: 2421-2431.

[50] Hogan LH, Klein BS. Altered expression of surface alpha-1,3glucan in genetically related strains of Blastomyces dermatitidis that differ in virulence. Infect Immunol 1994; 62: 3543-3546.

[51] Rementeria A, Lopez-Molina N, Ludwig A, et al. Genes and molecules involved in Aspergillus fumigatus virulence. Rev Iberoam Micol 2005; 22: 1-23.

[52] Stone BA, Clarke AE. Chemistry and biology of (1-3)-B-glucans. La Trobe University Press: Bundoora, Australia, 1992.

[53] Barsanti L, Vismara R, Passarelli V, Gualtieri P. Paramylon ( $\beta-1,3-$ glucan) content in wild type and WZSL mutant of Euglena gracilis. Effects of growth conditions. J Appl Phycology 2001; 13: 59-65.

[54] Lee JH, Mullins M. Cytoplasmic Water-Soluble [beta]-Glucans in Achlya: Response to Nutrient Limitation. Mycologia 1994; 86: 235-241.

[55] Miyazaki T, Yasuta N. Chemical structure of the water-soluble glucan from the cell wall of Cladosporium herbarum. Studies on fungal polysaccharide. Chem Pharm Bull 1974; 22: 2058-2063.

[56] Sward-Nordmo M, Almeland T, Aukrust L. Variability in different strains of Cladosporium herbarum with special attention to carbohydrates and contents of two important allergens. Allergy 1984; 39: 387-394

[57] Schram-Bijkerk D, Doekes G, Boeve M, et al. Exposure to microbial components and allergens in population studies: a comparison of two house dust collection methods applied by participants and fieldworkers. Indoor Air 2006; 16: 414-425.

[58] Schram D, Doekes G, Boeve M, et al. Bacterial and funga components in house dust of farm children, Rudolf Steiner school children and reference children - the PARSIFAL Study. Allergy 2005; 60: 611-618

[59] Giovannangelo M, Nordling E, Gehring U, et al. Variation of biocontaminant levels within and between homes - the AIRALLERG study. J Expo Sci Environ Epidemiol 2007; 17: 134140.

[60] Douwes J, Doekes G, Heinrich J, Koch A, Bischof W, Brunekreef B. Endotoxin and $\beta(1-3)$-Glucan in house dust and the relation with home characteristics: a pilot study in 25 German houses. Indoor Air 1998; 8: 255-263.

[61] Rylander R, Fogelmark B, McWilliam A, Currie A. (1->3)-beta-Dglucan may contribute to pollen sensitivity. Clin Exp Immunol 1999; 115: 383-384.

[62] Roslansky P, Novitsky T. Sensitivity of Limulus amebocyte lysate (LAL) to LAL-reactive glucans. J Clin Microbiol 1991; 29: 24772483.

[63] Pickering JW, Sant HW, Bowles CA, Roberts WL, Woods GL. Evaluation of a (1->3)-beta-D-glucan assay for diagnosis of invasive fungal infections. J Clin Microbiol 2005; 43: 5957-5962.

[64] Osborne M, Reponen T, Adhikari A, et al. Specific fungal exposures, allergic sensitisation, and rhinitis in infants. Pediatr Allergy Immunol 2006; 17: 450-457.

[65] Douwes J, Zuidhof A, Doekes G, et al. (1->3)-beta-D-glucan and endotoxin in house dust and peak flow variability in children. Am J Respir Crit Care Med 2000; 162: 1348-1354. 